\title{
SHORT POSITION DISCLOSURES AND UNDERLYING STOCK PERFORMANCE: EVIDENCE FROM POLISH STOCK MARKET
}

\author{
Mateusz Dadej \\ Faculty of Economics, University of Gdańsk \\ ORCID: https://orcid.org/0000-0002-1791-7611
}

\begin{abstract}
After introducing EU Regulation on short selling and certain aspects of credit default swaps, in 2012, investors holding a significant short positions are obliged to disclose it in a public manner, through the local supervisor registry. Beside the intended transparency, such a registry also have a cogent influence on behaviour of market participants. The Multimillion euros worth of short position is a strong view on underlying stock perspective, to say the least. Thus, many investors do care about the public disclosures of short positions and some of them manage their portfolios accordingly. The aim of herein paper is to provide quantitative assessment of stock performance following short position announcement and present activity of short selling investors on Polish stock market. The research hypothesis verified in this study stated that the prices of short sold stocks are exhibiting significant downward trend relative to the benchmark in a half a year period after disclosure.
\end{abstract}

Key words: short selling, capital market, stocks, investments, investment funds.

JEL Class: G11, C12. 


\section{INTRODUCTION}

The initial idea that emerges whenever investor realize the overvaluation of his particular position is to sell it immediately, in order to omit potential losses. However, the early advancement in finance provided a way to not only avoid decline in a value of position but to embrace it as well. Short selling is one of the few methods to profit on declining prices of underlying security. Moreover, it is not only used to simply profit in a bear market but also to execute more complex trading strategies such as statistical arbitrage, pairs trading or hedging.

Despite the possibilities it offers, the concept of short selling (especially stocks) is still controversial among regulators, investors and executives of public companies [El Hedi Arouri et al. 2012: 140-141; www1, access 3.03.2020; www2, access 16.03.2020; www3, access 17.03.2020]. Besides some subjective accusations like immorality of profiting from others misfortune or speculation, there are also more objective claims about, for example, amplifying downward prices pressure that can result in self-fulfilling decline [Brunnermeier and Oehmke 2014: 2153-2195] or even undermining banking sector stability [Liu 2015: 814 -830]. That is why, short selling is often strictly regulated, especially during financial crises, when it is commonly outlawed. One notable regulation, in the context of this work, is EU Regulation on Short Selling and certain aspects of credit default swaps, which requires investor to disclose their net short position above fixed amount [Regulation (EU) N 236/2012 [act 2]] (currently, 0.1\% of total free float [www4, access 17.03.2020]). As one may suppose, the listing of a given stock in such a report is not favourable for its underlying stock, since institutional investors possess superb intellectual resources over other market participants and can influence the market as a consequence of their investments.

The purpose of the herein paper is to quantitatively describe activity of short selling investors and to analyse reactions to the publication of short net position of stock prices and their mid-term performance. The empirical evidence is based on companies listed on a Polish stock market. Main hypothesis of this paper is that stocks, that are subject to the short position disclosure are significantly underperforming their benchmark, in the following half a year period.

The following study is based on dataset of historical short positions held on companies listed on Polish stock market, as published by Polish Financial Supervision Authority. In order to compare performance of the underlying stock, the study also uses data of their historical prices. Additionally, descriptive part of the study draws firmly from economic literature concerning financial markets and legal sources that regulates short selling in UE. 


\section{MECHANISM OF SHORT SELLING}

Short selling is essentially, selling financial assets that are not property of an investor. The process of short selling begins with finding a counterparty that is able to lend an asset of choice. Most often, the lending counterparty is a broker or an institutional investor, who intends to hold those assets for long term, regardless. Investor have to provide collateral that is equal to the value of borrowed assets, in case of any default. The lender acquires adequate interest from an investor as well as from investing collateral. Usually, the lender returns part of the interest received from a collateral as a rebate rate therefore, an actual cost for investor is the difference between interest on borrowed asset and rebate rate. Immediately after receiving financial asset, investor sell it on the market. If the expectations of investor about asset price are met, i.e. prices fell, then he is able to buy the same amount of assets for lower price, effectively profiting from fell of market price of its liabilities. Along with giving borrowed assets, the lender returns the collateral. In case of increase in a price of a security, the investor is obligated to equally provide additional collateral on a daily basis, which is commonly known as margin call [Fabozzi et al. 2004: 9-11].

Short selling process can be primarily executed in twofold way. First one is called covered short selling, when an investor is borrowing a desired asset, the transaction formally occurs. The other process is called naked short selling. It is a selling of desired asset without borrowing it before, so the investor is explicitly „promising” to a buyer that he will give that asset in future. In order to close the position, an investor shall buy given asset and fulfil his promise. The later method of executing short selling is associated with higher risk, from individual as well as from systematic risk perspective.

There are, however, some notable drawbacks of short selling. First one is its disability to achieve higher rate of return than, approximately, $100 \%$ during a single transaction. The reason is purely economical, value of a given financial asset cannot have lower price than zero (at least, it has not occurred hitherto), thus the price cannot lose more than its total current value. However, this disadvantage might be omitted with leverage or by realising profit and reinvesting it in the same investment subsequently. Additionally, the potential loss from investment is theoretically infinite, for there is no constrain as to how elevated the price of many asset can potentially be.

Other noteworthy disadvantages are rather of logistic nature. It is possible for a short seller to happen on buy-in, which is basically the sudden request from lender to get his assets back, resulting in necessity for an investor to cover its position and buy those assets from the market. Unforeseen pull back from a lender can result in an inappropriate execution of investment strategy, which is more painful the more complex strategy is. 


\section{SHORT SELLING ON WARSAW STOCK EXCHANGE AND EUROPEAN MARKETS}

Short selling in Poland may not be as popular as in more developed financial markets, although it is still practiced among market participants. It is available to investors since introduction of adequate ordinance of the Council of Ministers in 1999, however it was not in use by many traders due to tax ambiguity and rigid legal framework. Currently it is regulated by the Act of 29 July 2005 on financial instruments trading [act 1] which incorporates among others the Regulation N 236/2012 of the European Parliament and of the Council of 14 March 2012 on short selling and certain aspects of credit default swaps ${ }^{1}$ - hereinafter referred to as Regulation N 236/2012 [act 2]. The lending agreement itself is in line with the standards of the International Securities Lending Association. Since incorporation of the European Parliament Regulation, Warsaw Stock Exchange is no longer responsible for gathering data about short selling, marking short selling transaction in order book and publishing list of allowed stocks. Despite of this, most brokerage houses allow a limited amount of stocks for short selling in their offer.

There are some noteworthy legal implications concerning short selling from de facto applicable regulations in Poland, as well as in every EU member state. Since the Regulation N 236/2012 was introduced following the Great Financial Crisis, most of the changes are restricting given practice as it is considered to aggravate the downward spiral in the prices of shares and thus increasing financial instability. One of the main consequences is banning naked short selling, which is advocated to decrease settlement risk and volatility in general, as described in previous chapter. In regard to the settlement, a Regulation N 236/2012 is also enforcing a presence of a third party, that has confirmed location of the shares and make them available for the settlement.

As a consequence of the Regulation N 236/2012, ESMA (European Securities Market Authority) has a crucial role in supervising short selling practice in European Union. This entity is responsible for coordinating regulatory actions taken by home financial authorities toward short selling practice and ensuring consistent approach. This is especially the case in competing markets or those at which market participants can invest in the same instrument, which is subject to potential regulatory constraints. Besides some mild influence in regulatory actions, like expressing opinions, ESMA, in exceptional circumstances can directly prohibit or impose conditions on short selling by a given legal or natural person. The aforementioned, exceptional circumstances are present if a home authority have not taken any sufficient action toward a market participant, that actions pose a risk to the stability of financial markets.

${ }^{1}$ The definition of short selling in referred regulation is consistent with the one described at the beginning of the paper. 
Although, the most essential part of a Regulation N 236/2012 current regulatory framework, in regard to this paper, is the obligation to publicly disclose net short position above given fixed threshold, which at the moment of introduction was $0.2 \%$ [www5, access 6.03.2020] and currently is $0.1 \%$, additionally at each $0.1 \%$ increment above that. Short net position is defined as the difference between short and long positions. The rationale behind this enforcement is twofold. To aid regulators in monitoring and investigating possible market abuses, like insider trading or price manipulation, that are harmful to other investors. Second reasoning is to provide beneficial information to market participants, thus enhancing information efficiency of financial markets. The obligation expands the range of investments that are subject to disclosure to ,entering into a transaction which creates or relates to a financial instrument [...] where the effect or one of the effects of the transaction is to confer a financial advantage on the natural or legal person entering into that transaction in the event of a decrease in the price or value of the share or debt instrument" [act 2], essentially including derivative instruments, that allow to hold a short position as well.

\section{SHORT POSITIONS - EXPLORATORY DATA ANALYSIS}

Main analysed data is sourced from Polish Financial Supervisory Authority's short selling registry. The dataset is updated since the introduction of a Regulation $\mathrm{N} \mathrm{236/2012} \mathrm{in} \mathrm{2012,} \mathrm{with} \mathrm{the} \mathrm{first} \mathrm{published} \mathrm{short} \mathrm{position} \mathrm{on} 1^{\text {st }}$ of November 2012. The raw dataset downloaded was processed and cleaned from unnecessary variables and records of short positions on currently delisted stocks, which historical share price data is hard to obtain. This may pose a risk of survivorship bias. However those lacking stocks have minimal participation in dataset and as is usually the case, are downwardly biased. As of the moment, during which, the herein work is being written, the final dataset consists of 823 records ( 854 before data cleaning process). Final dataset has 4 variables, name of the investor, stock upon which the short position is being held, date of the disclosure and short net value as a percentage of total free float [www6, access 30.03.2020]. What should be noted before falsely inferring further from this dataset is that this data does not include most of the short positions held, there are only positions above threshold valid at a given time. Moreover, investors prefer not to disclose their position, in order to keep their net short position below if possible, therefore the distribution have a significant accumulation directly after the threshold.

As it is shown in Table 1 Investor, that held disclosed short positions the most

often is Marshal Wace, a London-based hedge fund. Accounting for approximately $1 / 4$ of every short position disclosed. The concentration, in general 
is rather high, with top 5 institutional investors being responsible for $51 \%$ of every disclosure. Investors, that reported were mostly foreign institutional investors, although it is hard to specify exact number as the registry location might be de facto only virtual. The presence of foreign investors is not very surprising, given the internationalization of financial markets and immense disparity among level of Polish capital markets and those of highly developed Anglo-Saxon countries. The same concentration can be observed throughout the European Union as well, where UK and US based institutional investors reported around $70 \%$ of every short selling activity between 1 January 2013 and 31 December 2016 on European stock markets [Mazzacurati 2018: 61].

Table 1. Most active short position holders

\begin{tabular}{|c|c|c|}
\hline Investor & $\begin{array}{c}\text { Number of } \\
\text { Disclosures }\end{array}$ & $\begin{array}{c}\text { Average net short } \\
\text { position }\end{array}$ \\
\hline Marshall Wace & 218 & $0.636 \%$ \\
\hline FIL Investments International & 77 & $0.726 \%$ \\
\hline AQR Capital management & 59 & $0.926 \%$ \\
\hline FIL Fund Management & 34 & $0.593 \%$ \\
\hline Blue Ridge Capital & 32 & $0.942 \%$ \\
\hline BlackRock Institutional Trust Company & 31 & $0.598 \%$ \\
\hline
\end{tabular}

Source: own study based on data provided by Polish Financial Supervision Authority [www6, access 30.03.2020].

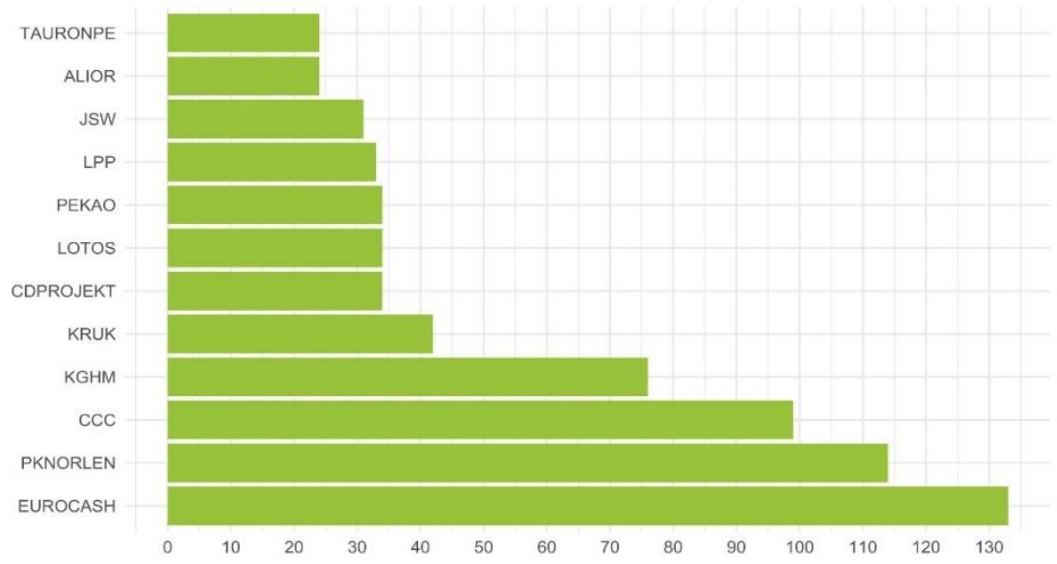

Chart 1. Frequency of short selling disclosure per company. Top 12

Source: own study based on data provided by Polish Financial Supervision Authority [www6, access 30.03.2020] and made with ggplot2 package in R programming language [Wickham 2016: 54]. 
Unsurprisingly, the most frequent stocks that were subject to short selling are also very liquid. Most of them are or were at a time included in most commonly referenced stock market indexes on WSE, i.e. WIG20 or mWIG40. Another reason for some of those companies to be shorted so often is a technical one. Simply put, the longer a company is listed the more chances it has to be a subject of short selling. For example, Eurocash is listed for almost 15 years, whereas PKN Orlen for 20 years. Perhaps because of lack of sufficiently liquid stocks, short selling activity is also very concentrated, with 4 most shorted stocks (Eurocash, PKN Orlen, CCC, KGHM) accounting for approximately $51 \%$ of every short positions registered, which is remarkable given the fact that there are currently 444 companies on main stock market alone [www7, access 9.04.2020]. From a foreign investor's portfolio perspective, in some cases, it is not the point to have an exposition for a specific factor of a company but rather to profit on decrease of the whole Polish capital market. Thus, the investment is meant to embrace the high beta of particular stock, i.e. its correlation to the benchmark. This is especially notable for PKN Orlen, which beta is around 0.99 for analysed period ${ }^{2}$.

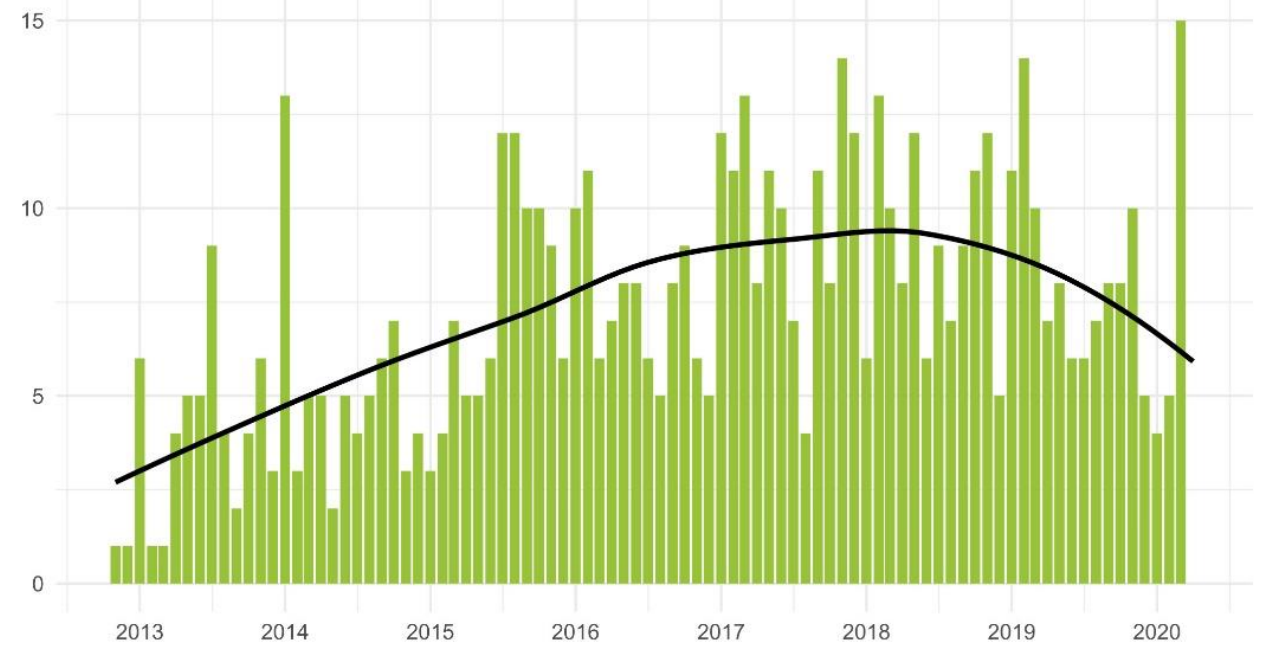

Chart 2. Monthly count of reported short selling activity. Black line is a local polynomial regression applied only for visualization purpose

Source: own study based on data provided by Polish Financial Supervision Authority [www6, access 30.03.2020] and made with ggplot2 package in R [Wickham 2016: 54 and 66]

${ }^{2}$ Own calculation with data from stooq.pl [www8, access 8.04.2020]. 
Even though, the Polish capital market has not been developing as fast as real sphere of Polish economy ${ }^{3}$, the short selling activity had steadily risen for the most part of reporting period. At least until end of 2017, when it started to decrease. During that year, there was the highest number of registered short position, amounting to 121 , which is significantly more than mere 50 short position announced in 2013. Month with the highest reported count of short positions was at the moment of writing this paper (March 2020) and was perhaps due to the sudden increase in volatility on Polish stock market, as well as on global financial markets. Given the fact that most of the short selling investors are foreign based, the increase might be a result of unification of short selling rules among whole EU following introduction of a Regulation N 236/2012. Which could reduce entry cost associated with analyzing local law and investment managers home bias in general. Investors eager to short sell are rather statistically indifferent with respect to broad market turnover, volatility and its returns. None of these variables are able to linearly explain their activity. This might support conjecture that foreign short selling investors are seeking, in most cases, factors that are specific to the underlying company, e.g. fundamental factors. Which is why, at the moment of being listed on short selling registry, $64 \%$ of shorted companies had price to earnings ratio higher than average for companies included in WIG and $1 / 4$ of them had 5 times higher aforementioned ratio ${ }^{4}$. The referenced investment metric is commonly applied to assess whether particular stock is undervalued given profits they generate, i.e. expected returns are favorable [Hitchner 2011: 200].

\section{PERFORMANCE OF SHORT POSITIONS}

New positions on short selling register is often subject of great interest from investors on Polish stock market. As well as in related news media [www9, access 8.04.2020; www10, access 8.04.2020; www11, access 25.03.2020] as on financial blogposts [www12, access 1.04.2020; www13, access 1.04.2020]. Recent listings on short selling register is usually discussed in context of potential fall of shorted share prices. The shorting activity itself will not directly influence fundamentals of company, nor in most cases its price per share. Although, it might prompt investors to change their perspective toward given company. There are several rationales behind such persuasion. First of all, institutional investors, in comparison to individual ones, possess superb intellectual resources and time, which allow them to perform better analysis toward potential investments.

3 E.g. mean monthly volume has not changed significantly for the analogical period, as well as number of listed companies.

${ }^{4}$ Own calculation with data from stooq.pl [www8, access 8.04.2020]. 
Moreover, institutional investors not only better analyze public information, but also acquire non-public, insider information, which they may utilize to execute successful investments with abnormal rates of return [Ali et al. 2004: 221-248]. Above reasoning also has its consequences as a self-fulfilling prophecy, when market participants realize about those asymmetries and tries to adjust their investment holdings adequately, exaggerating further decrease of prices. Even though, most of the investors have limited or no access to financial instruments that enable short positions, it is still valuable to identify potential headwinds as it is possible to at least close long position. Or in more sophisticated case, create enhanced indexing portfolio.

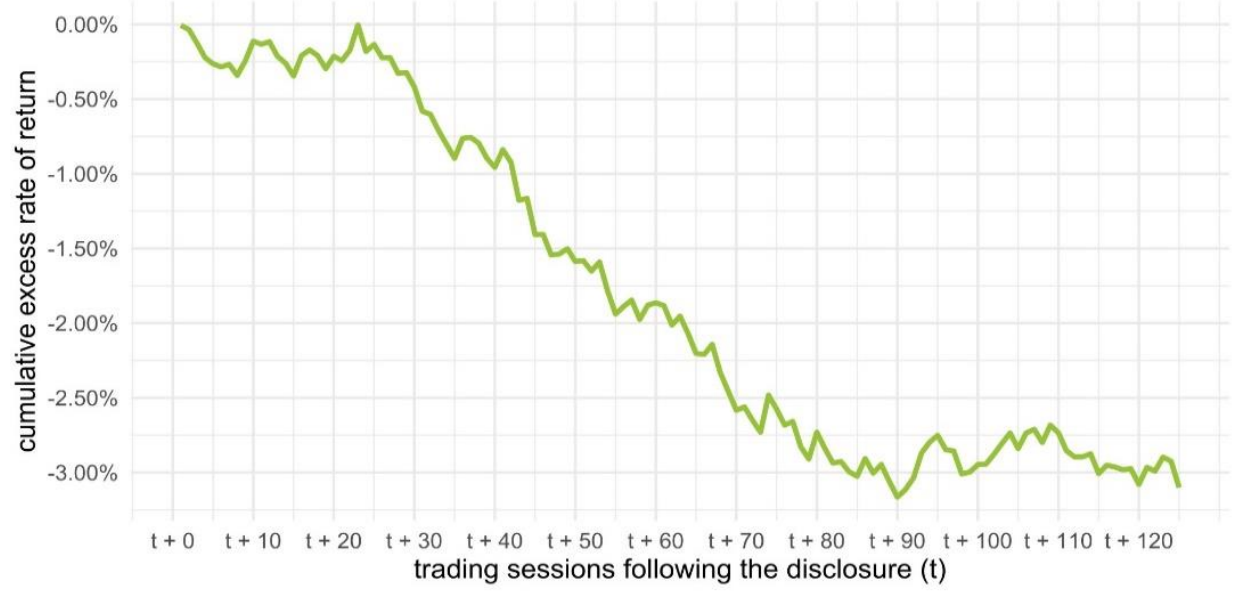

Chart 3. Mean path of each stock. Cumulative rate of return for a hypothetical portfolio of shorted stocks. 125 trading sessions after disclosure

Source: own study based on data provided by Polish Financial Supervision Authority [www6] and made with ggplot2 package in R [Wickham 2016: 27]

With all of the aforementioned phenomena having in mind, it seems appropriate to investigate the actual quality of signal following short position disclosure in a quantitative manner. In order to initially assess such a performance, the author made hypothetical portfolio of stocks from different time frames of equal length, but each of them after the disclosure. To compare performance relative to the benchmark, the rates of return were adjusted for $\mathrm{WIG}^{5}$ index returns

${ }^{5}$ WIG is not a proper benchmark for calculating excess returns in the commonly acclaimed sense [e.g. in Ang 2014: 307] but for the purpose of herein analysis it is crucial to distinguish short position disclosure effect and market factor. 
at the parallel time frame, thus representing (negative) excess rates of return [Stewart et al. 2019: 210]. The weighs were assigned in very uncomplicated manner, with $1 / n$ allocation strategy, which gives equal weights for every position, where $n$ is number of stocks and is equal to 843 [DeMiguel et al. 2009: 1916]. This allocation method has favourable feature that allows to interpret returns also in average terms. Chart 3 shows cumulative performance of that portfolio, for 125 trading sessions, which corresponds to approximately half a year. The curve exhibits a clear downward trend after 20 trading sessions, which can suggest that there is, indeed, some pattern after the short position announcement. During that timeframe, the portfolio decreases by $3,1 \%$ relative to chosen benchmark and $2.7 \%$ in absolute terms, which gives a hypothetical positive rate of return, since short positions have payoff function that is inverse to the one of long positions. After shown 125 trading sessions above, cumulative rate of return is entering into consolidation, without any visible trend or pattern. The volatility of the portfolio is rather low, although it has decreased artificially due to the diversification effect. It shall be noted here, that this cannot answer the question whether institutional investors are profitable on their short positions, since there is no data on closure of position and the announcement itself can occur after previous accumulation of short positions, thus it is also possibly not an opening of the position for particular fund. As aforementioned, an institutional investor can also hold particular short position in order to hedge or execute more complex strategy, hence it might not be intent for the position to be individually profitable.

It is obviously tempting to find if the return is statistically different from zero. To do so, we will analyse variable consisting of returns after 125 trading sessions for each short position historically disclosed. The data of stock returns as it usually occurs is not normally distributed ${ }^{6}$, thus it is necessary to use non-parametric hypothesis testing ${ }^{7}$. However, it is distributed symmetrically, thus it is appropriate to use one sample Wilcoxon Signed Rank Test [Deshpande et al. 2018: 90]. Hypothesis testing can be limited to one-tail test, for it is sufficient for the tested hypothesis, that the true location of returns is less than zero. And so, the hypotheses, related to the one from the beginning of the paper, can be stated as follows:

$$
\begin{aligned}
& H_{0}: \text { median }\left(r_{e}\right)=0 \\
& H_{1}: \operatorname{median}\left(r_{e}\right)<0
\end{aligned}
$$

\footnotetext{
${ }^{6}$ Confirmed with Shapiro-Wilk test on normality, $p<.0056$.

${ }^{7}$ Although, t-test provides the same conclusion as shown later on.
} 
Outcome of statistical test of choice is favourable for main hypothesis. The $p$-value of Wilcoxon Signed Rank test is less than .01, hence we shall reject the $H_{0}$. The median of the total excess return half a year after short position disclosure on a given stock is negative. We can further conclude that, in most cases the return of the shorted stock will underperform benchmark after half a year from the moment of short disclosure. Both inferences above can be stated at $0.1 \%$ significance level.

\section{CONCLUSIONS}

Herein research fills the void in economic literature concerning particular aspects of short selling by characterizing activity of institutional investors engaged in short selling activity and the way public disclosure of their short positions influence underlying stocks. The evidence indicates that publishing short position have a statistically significant, although not exceptionally large, effect on following performance of underlying stocks. Additionally, the short selling activity of institutional investors, which is diminishing in recent years on the Polish stock market, is in most cases oriented around factors specific to the shorted company, i.e. its fundamental value nor to the whole market factor.

The short positions registry, indeed, should be a valuable source of information for a conscious capital market participant. Every investor should realize that stocks of companies that are listed on the registry could have significant headwinds of increase in their prices per share. However, the stock market is a very complex system with multidimensional characteristics. There are immense quantities of factors that can influence prices and most of them hard to directly observe. Even though, the announcement of net short position by institutional investor happens to play a significant role for the future path of stock prices, one should not blindly follow main conclusion presented in previous part of the paper. As always, every investment case should be analysed separately, for there are countless of interrelated factors, that may change the context in which, for example, short selling disclosure affect perspectives of underlying stock.

The excess returns presented also shows that, there is indeed some room for improvement in aspect of informational efficiency of Polish stock market. The disclosure shows unexploited opportunities in stock prices, perhaps due to limited availability of financial instruments that allows for opening short positions. Thus, it is in line of some scientific papers, pointing out benefits of short selling accessibility for financial market efficiency.

For further assessment of short position announcements as a trading signal, it might be appealing to perform investment strategy backtest. For example, with additional assumptions about availability of financial instruments, the given 
investment strategy might be set to short sell next day after the disclosure and hold for a specified time, with given betting method for current listed shorts. This might be useful to additionally asses benefits of omitting those stocks from investor's trading suite.

\section{BIBLIOGRAPHY}

Ali A., Durtschi C., Lev B., Tromble M., 2004, Changes in Institutional Ownership and Subsequent Earnings Announcement Abnormal Returns, „Journal of Accounting, Auditing \& Finance”, vol. 19(3).

Ang A., 2014, Asset Management: A Systematic Approach to Factor Investing, Oxford University Press.

Brunnermeier M.K., Oehmke M., 2014, Predatory short selling, „Review of Finance”, vol. 18.

DeMiguel V., Garlappi L., Uppal R., 2009, How inefficient is the 1/N assetallocation strategy?, „Review of Financial Studies”, vol. 22, no. 5.

Deshpande J.V., Naik-Nimbalkar U., Dewan I., 2018, Nonparametric Statistics: Theory and Methods, World Scienific Publishing.

El Hedi Arouri M. et al., 2012, Are Restrictions on Short Selling Good? A Look at European Markets, [in:] Handbook of short selling, Elsevier.

Fabozzi F. et al., 2004, Short Selling Strategies, Risks, and Rewards, Wiley Finance.

Hitchner J.R., 2011, Financial Valuation: Applications and Models, Wiley.

Liu X., 2015, Short-selling attacks and creditor runs, „Management Science”, vol. 61, issue 4.

Mazzacurati J., 2018, The public disclosure of net short positions, [in:] ESMA Report on Trends, Risks and Vulnerabilities.

Stewart S.D., Piros C.D., Heisler J.C., 2019, Portfolio Management: Theory and Practice, Wiley.

Wickham H., 2016, ggplot2 Elegant Graphics for Data Analysis, Springer.

[act 1] Ustawa z dnia 29 lipca 2005 r. o obrocie instrumentami finansowymi.

[act 2] Regulation (EU) No 236/2012 of the European Parliament and of the Council of 14 March 2012 on short selling and certain aspects of credit default swaps.

[www1] https://markets.businessinsider.com/news/stocks/tesla-spacex-ceo-elon-musk-shortselling-should-be-illegal-2019-12-1028733903 [access 3.03.2020].

[www2] https://www.money.pl/gielda/ccc-cierpi-na-kryzysie-chce-przywrocenia-niedzielhandlowych-6489590924154497a.html [access 16.03.2020].

[www3] https://nypost.com/2020/03/17/wall-street-investors-urge-white-house-to-curb-shortsellers/ [access 17.03.2020].

[www4] https://www.esma.europa.eu/press-news/esma-news/esma-requires-net-short-positionholders-report-positions-01-and-above [access 17.03.2020].

[www5] https://www.esma.europa.eu/regulation/trading/short-selling [access 6.03.2020].

[www6] https://rss.knf.gov.pl/RssOuterView/ [access 30.03.2020].

[www7] https://www.gpw.pl/gpw-statistics [access 9.04.2020].

[www8] www.stooq.pl [access 8.04.2020].

[www9] https://strefainwestorow.pl/artykuly/spolki/20200306/dino-polska-spadki [access 8.04.2020].

[www10] https://strefainwestorow.pl/artykuly/analizy/20200319/kruk-szort-zysk [access 8.04.2020]. 
[www11] https://www.parkiet.com/Analizy/303059944-Jest-szansa-na-rozwoj-krotkiejsprzedazy.html [access: 25.03.2020].

[www12] https://gpwatak.pl/inne/rejestr-krotkiej-sprzedazy-warto-sie-nim-sugerowac/ [access 1.04.2020].

[www13] http://humanista-na-gieldzie.blogspot.com/2014/07/krotka-sprzedaz-na-gpw-okieminwestora.html [access 1.04.2020]. 